\title{
The General Medical Council's medical ethics education conference
}

\author{
Sir John Walton President, General Medical Council
}

\section{Editor's note}

Early in 1984 the General Medical Council held a one-day conference on the teaching of medical ethics. This issue of the journal is largely devoted to presentations given at that conference, some of which were subsequently modified for publication.

Readers of the Fournal of Medical Ethics will not need to be reminded that the rules and principles which govern the ethical behaviour of the medical profession and the relationships between its members on the one hand and the public on the other have been to a considerable extent based upon recommendations which probably began with Hippocrates but which have been modified, expanded and remoulded over the centuries in consequence of the changing needs and attitudes of society. Nor will readers be unaware that developments in medicine and medical science, within the last 50 years in particular, have posed new problems and have raised new and challenging ethical dilemmas. In consequence many organisations, national and international, medical and lay, have begun to study these problems and have offered advice

\section{Key words}

Medical ethics education; General Medical Council. to the profession, seeking modifications in its ethicalo codes. Some such changes have indeed been imposed $\exists$ by changes in the law, but most have been introducedby the profession itself with the benefit of informed lay? opinion and advice.

While certain basic principles survive which are $\vec{z}$ generally accepted internationally, there are many significant differences in the ethical codes now in existence in different countries. In the United Kingdom, the Medical Act of 1978, consolidated in 1983, gave power to the General Medical Council, the profession's national regulatory body, to give 'advice? for members of the medical profession on standards of professional conduct or on medical ethics'. This is a⿳亠二口犬 responsibility which the council has taken and is takingo very seriously. In the pages which follow, Professor Arthur Crisp first expands upon the role of the council $\vec{\circ}$ and its committees and then papers based on the 3 proceedings of a conference which the council held on The Teaching of Medical Ethics in February, 1984 are given in full. I hope these will prove of interest to readers of this journal and will indicate the increasing attention which the council is paying, and will continue to pay, to this important subject. 